\title{
Ecological Production Technology of Phenoxyacetic Herbicides MCPA and 2,4-D in the Highest World Standard
}

\author{
Wiesław Moszczyński and Arkadiusz Białek \\ The Institute of Industrial Organic Chemistry, \\ Poland
}

"Selectivity is a major goal in modern synthetic chemistry"

Bartman W., Trost B. M.

\section{Introduction}

Herbicides MCPA (4-chloro-2-metylphenoxyacetic acid) and 2,4-D (2,4-dichlorophenoxyacetic acid), which belong to the group of chlorophenoxyacetic acids, have been produced in Poland since the break of the sixties in the scale of many thousands of tons per year, which constitutes $5-7 \%$ of the world's production. Acids and their salts are exported to all continents. An advantage of herbicides within this group is their harmlessness for man and environment in doses used in agriculture. The condition is the high content and purity of the active substance in utility preparations. Unfortunately, classic technologies based on the reaction of phenols chlorination or their derivatives used until today all over the world do not ensure high purity, and significant quantities of highly toxical chloroorganic waste compounds originate in the production process. The main cause lies in the low selectivity of the reaction of chlorination of phenols' aromatic ring. Numerous producers enrich the purity of chlorophenols with the method of rectification. As our research has shown, in the process of rectification and while burning post-rectification wastes, dioxines and dibenzofurans can originate.

Below we present research conducted in the Institute of Industrial Organic Chemistry (IPO) in Warsaw with strict cooperation with production plants „Rokita Agro” in Brzeg Dolny and "Organika Sarzyna" in Nowa Sarzyna over the development of technologies of chlorophenoxyacetic herbicides. Commonly used "classical" technologies of production of MCPA and 2,4-D are based on two subsequent reactions - chlorination of phenol or 2methylphenol and the reaction of the obtained chlorophenol with chloroacetic acid (MCAA), commonly called condensation. The first stage - chlorination reaction - is critical for the nature of the entire reaction, i.e. the number of operations, selection of equipment, purification methods, wastes. Electrophilic reaction of chlorination of aromatic phenol ring is non-selective. Isomers and polychlorinated compounds are always originated. In order to increase the selectivity of reaction and the purity of the the final product, various technologies of chlorination and purification of chlorophenols are used all over the world, 
including regioselective catalysts, replacement of chlorine with sulfuryl chloride, rectification of chlorophenol and reversed technologies, i.e. condensation first, and then chlorination of the obtained phenoxyacetic acid. Also in our country technologies of production of MCPA and 2,4-D have been changed many times, achieving higher and higher selectivity of the chlorination reaction. The current production of MCPA (Chwastoks) is based on a unique technology of chlorination of $98 \%$ selectivity, while in the 2,4-D technology $96 \%$ selectivity has been achieved, and after crystallization it ensures the purity of the product equal to $98 \%$. Technologies minimize or eliminate waste chloroorganic compounds. The final products have the highest quality standard.

\section{MCPA}

In the years 1959-1961 in IPO-Warszawa an experimental production MCPA in the scale of 5 tons per year of $30 \%$ "Chwastoks R-30" preparation was started. It made possible the conduct of vast agricultural research, including the research at 15500 linum plantations. In 1962 in Nowa Sarzyna was started the first technical installation of 1000 tons of Chwastoks R-30 (Moszczyński et al, 1963). The synthesis was based on chlorination of 2-methylphenol with gaseous chlorine. Technical 4-chloro-2-methylphenol without purification was exposed to condensation with monochloroacetic acid (MCAA). The diagram of the reaction is presented below.<smiles>Cc1cc(Cl)ccc1OCC(=O)O</smiles>

2-methylphenol 4-chloro-2-methylphenol

2-methyl-4-chlorophenoxyacetic acid

(MCPA)

The reaction of chlorination of melted 2-methylophenol had a very low selectivity - 60 to $70 \%$. Technical 4-chloro-2-methylphenol was a mixture of chlorophenols of the following composition:

$\begin{array}{ll}\text { 4-chloro-2-methylphenol } & 60-70 \% \\ \text { 6-chloro- } & 12-20 \% \\ \text { 4,6-dichloro- } & 3-9 \% \\ \text { 2-methylphenol- } & 4-10 \%\end{array}$

After the condensation of technical 4-chloro-2-methylphenol with chloroacetic acid there was derived a mixture of chloromethylphenoxyacetic acids containing 60 to $70 \%$ of MCPA. Below such a product is referred to as "MCPA 70". In the process of condensation the efficacy varied within broad limits and there always remained several per cent of nonreacted chloromethylphenols.

The final product Chwastoks R-30 was separated from the post-condensation mass without purification, the preparation contained up to $6 \%$ of free chloromethylphenols. A similar MCPA technology was applied by many producers, e.g. in Leuna-Werke plants, GDR, where the raw post-chlorination mixture was exposed to vacuum rectification. Together 
with that $40 \%$ of waste chloromethylphenols was originated. The preparation Chwastoks R30 had a good opinion among its users. It did not freeze in winter in unheated warehouses, it perfectly dissolved in water. It was cheap. In IPO a comparative research of the activity of MCPA-70 with pure MCPA was conducted, and the activity of each chloromethylphenoxyacetic acids separately, and also their mixtures. It appeared that isomeric 6-chloro-2-methylphenoxyacetic acid had a high biological activity, and in the mixtures the synergism of activity was observed. After 10 years of MCPA-70 production in a small installation in 1972 a new production facility of 4500 tons per year capacity was started without substantial changes in technology. In the discussed decade in the European market there appeared MCPA preparations of high purity, without free chloromethylphenols containing $80-90 \%$ of the pure active component. In the technologies sulfuryl chloride was used as a more selective chlorinating agent, and sometimes additionally vacuum rectification of technical 4-chloro-2-methylphenol. Chemische Werke Schwarzweide in GDR started the production of MCPA basing on sulfuryl chloride on the license purchased in Great Britain. The technology based on sulfuryl chloride is currently commonly used by chemical companies all over the world.

Skeeters was the first to describe in 1956 the MCPA synthesis through chlorination of 2methylphenoxyacetic acid (MPA) in 1,2-dichloroethane (Skeeters et al., 1956). In the seventies such a method was used in industry. It was a new generation technology, below referred to as the reverse method, and the obtained product - "MCPA 90". The diagram of the reaction is presented below.<smiles>Cc1cc(Cl)ccc1OCC(=O)OCC(=O)O</smiles>

2-methylphenol

2-methylphenoxyacetic acid

(MPA)

MCPA

The aromatic ring of MPA acid is less prone to electrophilic substitution, and the side chain is a steric hindrance for creating the isomer 6-chloro-. In the reaction of MPA, chlorination selectivity of $80-90 \%$ is achieved, i.e. higher than in the classical method, where sulfuryl chloride without purification of the product by rectification is used. In the reverse technology a barrier which is difficult to lift is the high melting temperature of MPA $\left(157^{\circ} \mathrm{C}\right)$ and the low solubility $(7 \%)$ in organic solvents. Chlorination of MPA acid without solvents in hot water cannot be performed to the end and there remains $20 \%$ of non-chlorinated MPA. In Bratysława, the chlorination of $20-30 \%$ of water solution of MPA sodium salt MPA in the temperature of $90-100{ }^{\circ} \mathrm{C}$ was used on the industrial scale. The final product, containing $90 \%$ of the active substance, contained $5 \%$ of isomer 6 -chloro- and $3-6 \%$ of free MPA (Rapoš et al, 1960). Chimzawod in Ufa, USSR, launched a multi-ton installation of MPA acid chlorination in 7\% solution in solvent. The license with the full equipment was purchased from the Fisons company (Great Britain). The MCPA purity was $85-90 \%$, the product contained 1-3\% of free MPA, efficiency about 92\% (Moszczyński, 1971). 
In Poland, in 1976, after the complete redevelopment of MCPA-70 system (Moszczyński et al., 1975), a new generation reverse technology was developed and used in industry. MPA acid heated with tetrachloroethylene (TCE) in post-condensation mass (brine) forms an eutectic of melting temperature of $100^{\circ} \mathrm{C}$. It enables the separation of the liquid organic phase MPA/TCE from brine effluent from the post-condensation mass. The ogranic phase of MPA/TCE without drying was chlorinated in the temperature of $90-100 \%{ }^{\circ} \mathrm{C}$. TCE was removed from the post-chlorination mass with the use of destillation with water vapour. The obtained product was of $90 \%$ purity, with a mix of 7-9\% of isomer 6-chloro-, and up to $3 \%$ of free chloromethylphenols. With the evaluation of efficiency in precise balance tests, 3 to $5 \%$ of the product was missing, and the quantity of free chloromethylphenols was higher that the quantity derived from MPA. In the technology used in Ufa, MPA before chlorination was effectively dephenoled by the extracting method, and in spite of that, in the final product chloromethylphenols were present. In patent literature the low efficiency of MPA chlorination attracts attention, as well as the lack of material balance of reaction. We have recognized that as a normal known phenomenon of breaking MPA and MCPA ether bonding in the presence of hydrogen chloride according to the following diagram:<smiles>Cc1cc(Cl)ccc1OCC(=O)O</smiles><smiles>Cc1cc(Cl)ccc1O</smiles>

The hydrolysis research which we performed did not confirm the presence of such a reaction in the conditions of MCPA synthesis, in the MPA post-chlorination mass there was found and separated several per cent and a compound with spirolactone structure was identified. An identical compound was depicted earlier by H. Lund (Lund, 1958).<smiles>CC1=CC(Cl)C(Cl)C(Cl)C12OCC(=O)O2</smiles>

$\mathrm{H}$. Lund suggests the mechanism of spirolactone origination, a derivative of MPA, based on joining 2 molecules of $\mathrm{Cl}_{2}$ to the aromatic ring before the formation of cyclic ketal (spirolactone) according to the diagram:<smiles>CC1=C[C@H](Cl)[C@H](Cl)[C@H](Cl)[C@]1(OC(=O)O)C(Cl)Cl</smiles>

He refers to known phenols reactions, which in the process of long-lasting chlorination, after saturation of all the places with chlorinum, form cyclohexanones. It is difficult to agree with 
such a mechanism, where in the chlorination of MPA with one chlorinum atom, in mild conditions, with the help of hypochlorite with the known susceptibility of phenol aromatic ring to replacement of $o$ - and $p$-, there might occur such a significant addition of chlorinum atoms. The life of cyclohexanone ring should not be conditioned by the presence of lactone side ring. Meanwhile, the reconstruction of the side ring transforms the cyclic structure into the aromatic one. W. Moszczyński suggests a completely different mechanism (Moszczyński, 1998). In the process of MPA chlorination after binding chlorinum atom in the electrophilic reaction there is formed a transitory sigma complex, which is subject to preservation in the intramolecular nucleophile trap according to the following diagram:

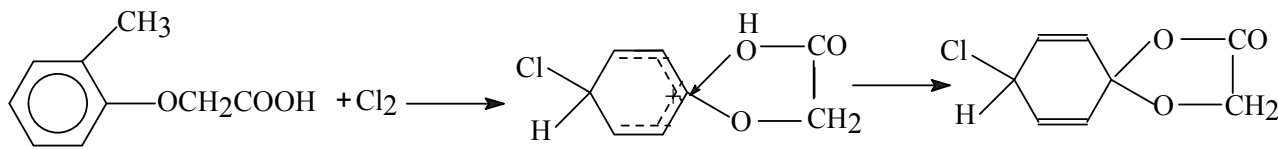

sigma complex

sigma complex preserved in the intramolecular nucleophile trap

The preserved sigma complex is easily disintegrated into chloromethylphenol and glycolic acid. The discussed reaction is of a general nature, we repeated it while chlorinating 2,4dichlorophenoxyacetic acid and chloromethylphenoxypropionic acid, obtaining appropriate preserved sigma complexes. Our discovery that chlorophenoxyalkanecarboxylic acids are traps of sigma complexes in electrophilic reaction of chlorination in the environment of organic solvents explains the causes of appearance of free chloromethylphenols and losses of the final product in the synthesis with the reverse method.

In MCPA production with the reverse method, the first stage was the synthesis of 2methylphenoxyacetic acid (MPA) in the Williamson's reaction according to the following diagram:

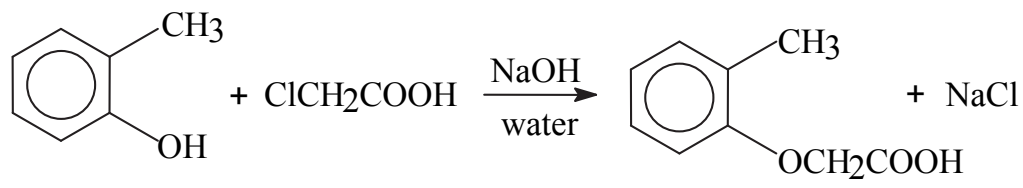

The main reaction is always accompanied by the side reaction of hydrolysis of chloroacetic acid into glycolic acid.

$$
\mathrm{ClCH}_{2} \mathrm{COOH} \underset{\text { water }}{\stackrel{\mathrm{NaOH}}{\longrightarrow}} \mathrm{HOCH}_{2} \mathrm{COOH}+\mathrm{NaCl}
$$

In the domestic industrial production of MPA and 2,4-D, for many years the efficiency of condensation calculated to chloroacetic acid varied within broad limits, achieving on average $85 \%$. Research conducted by W. Moszczyński with the use of regression function explained the causes of changeable efficiency (Moszczyński, 1999). Repetitively the efficiency of MPA synthesis of about $92 \%$ was achieved. It was established that the first 15 minutes of reaction are critical for the efficiency of the main reaction. In that time about $90 \%$ of MCAA reacts. The nucleophilic reaction of synthesis of MPA with Williamson's method proceeds according to the bimolecular mechanism according to the scheme: 


\section{$\mathrm{V}=\mathrm{k}[\mathrm{ArO}-]\left[\mathrm{ClCH}_{2} \mathrm{COO}^{-}\right]$}

In the temperature $<90^{\circ} \mathrm{C}$, in the water alkaline environment its speed is low, while in the temperature of $90-110^{\circ} \mathrm{C}$ full substract reaction occurs after 1 hour (Moszczyński, 1994). $\mathrm{pH}$ has very clear influence on this speed, and the concentration of ions of phenoxyl ArO - and hydroxyl $\mathrm{OH}$ - depends on $\mathrm{pH}$. Both mentioned nucleophilic agents compete with each other in the reaction with substract - apart from the main reaction there occurs hydrolysis of chloroacetic acid into glycolic acid. Hydrolysis of substract makes the reaction's kinetics more complicated, and the formula of speed of reaction of synthesis of MPA needs to be corrected.

Hydrolysis of chloroacetic acid has a course which is clearly distinct from the main reaction. According to Berhenke and Britton, it occurs both in acidic environment and in alkaline environment and in the range of $\mathrm{pH} 3-10$ it has similar speed. (Berhenke, Britton, 1946). Occurrence of hydrolysis both in the acidic and lightly alkaline environment as well as acceleration of speed of hydrolysis in the final stage of MPA synthesis along with sodium chloride accumulation proved by this research confirm that the reaction proceeds according to the mechanism $\mathrm{S}_{\mathrm{N}} 1$. With $\mathrm{pH}=11-11,5$ MCAA hydrolysis is $5,5 \%$, and with $\mathrm{pH}=12$ 12,5 it increases to $42 \%$, which suggests that with a greater concentration of $\mathrm{OH}^{-}$the reaction proceeds according to the bimolecular mechanism type $\mathrm{S}_{\mathrm{N}} 2$ with the participation of $\mathrm{OH}^{-}$ ions. This research confirms the findings of Dawson and Pycock (Dawson, Pycock, 1936) that the reaction of MCAA hydrolysis is a combination of mechanisms $\mathrm{S}_{\mathrm{N}} 1$ and $\mathrm{S}_{\mathrm{N}} 2$.

For research on the optimalization of parametres of MPA synthesis with the use of mathematical model the following parametres were accepted as critical: reagent molar ratio $\left(X_{1}\right)$, reagent molar ratio $\left(X_{2}\right), \mathrm{pH}\left(X_{3}\right)$. Optimum values of variables $X_{1}$ and $X_{2}$ marked by experiment and calculated for the synthesis of MPA are respecively 0,8-1, and 3,3-3,7 $\mathrm{mol} / \mathrm{dm}^{3}$.

$\mathrm{pH}$ of reaction environment has a critical influence on the efficiency of MPA synthesis. With $\mathrm{pH}<9,5$ MPA synthesis does not occur, while with $\mathrm{pH}>11$, ion ArO- loses in the competition with ion $\mathrm{OH}^{-}$. The optimum value of $\mathrm{pH}$ indicated on the mathematical model is $10-10,7$.

In the period of MCPA production with the reverse method in "Organika Sarzyna" in the seventies, countries classical technologies of chlorination of 2-methylphenol with sulfuryl chloride used in different were modernized. New regioselective catalysts combined with vacuum rectification of technical 4-chloro-2-methylphenol were commonly used. It meant an improvement of the purity of preparations with over 90 to $96 \%$ of active substance.

IPO for the third time has joined the competition in the market, overtaking, in terms of modernity, all technologies based on sulfuryl chloride. MCPA of $98 \%$ purity was offered directly from the synthesis, without purification and wastes, with an outstanding simplification of technology.

After several years of research on regioselective catalysts of chlorination of MPA with chlorinum, sodium hypochlorite and $t$-butyl, a laboratory synthesis "MCPA 98 " of $98 \%$ of purity of active substance was developed. In May 1992 a combined research-implementation team, composed of 25 specialists from IPO was assigned, W. Moszczyński, I. Górska et al., and 19 from „Organika Sarzyna”, including. T. Jakubas, J. Peć to conduct technical tests, 
supervising redevelopment of construction and to conduct the launch of production. Synthesis of MCPA 98 consisted in one-stage condensation of MCAA with $o$-cresol to MPA and chlorination of MPA in water in room temperature with the use of sodium hypochlorite against amine catalyst (Moszczyński et al., 1992). A simple laboratory technology appeared to be unrepeatable in industrial conditions. For two years of $1 / 2$-technical and technical tests not a single manufactured unit of product of $>94 \%$ purity was obtained.

In the laboratory in glass all syntheses without exception had selectivity and efficiency of 98$99 \%$. Meanwhile, with any multiplication of scale in glass and apparatuses from 501 to 2,5 $\mathrm{m}^{3}$ after exceeding the stage of about $2 / 3$ pure chlorination para- suddenly broke down and a product of $90-94 \%$ purity of isomer para- was originated. Only the research of $\mathrm{W}$. Moszczyński on the mechanism of reaction showed that we deal wigh a new, unknown in this group of compounds, aromatic free radicals reaction of 99\% selectivity (Moszczyński, 1998 ). Free radicals reactions, as opposed to ion reactions, are highly selective, but sensitive to the conditions of reactions and dozens of external agents, and anytime there may occur a break of chain generation of radicals and return to the ion mechanism of a lower selectivity. Phenol reactions occupy a special place in this group. They are subject to reactions with such free radicals, which in other cases are inactive. There are proofs that with the presence of unpaired electrones delocalized into the aromatic ring, the replacement only occurs into the location orto- or para- (Dermer \& Edmison 1957). The presence of free radicals was proved by EPR method at the University of Wrocław (Jezierski et al., 1999). It allowed to discover and eliminate radicals inhibitors and easily repeat the synthesis on an industrial scale. The installation launch took place in 1995. For the third time a new MCPA production installation was assembled with the full automatic control of the technological process and continuous chlorination and educing of MCPA acid. In the table below a standard of active substance of domestic MCPA was shown, according to the technology from 1976 and the last from 1996 with the purity declared in that time by leading western producers (Moszczyński et al. 2010). MCPA 98 from „Organika Sarzyna” is the best in all parametres.

\begin{tabular}{|c|c|c|c|c|c|}
\hline \multirow[t]{2}{*}{ No. } & \multirow[t]{2}{*}{ Parametres } & $\begin{array}{l}\text { MCPA } 90 \\
\text { "Organik } \\
\text { a } \\
\text { Sarzyna" } \\
1976\end{array}$ & $\begin{array}{c}\text { MCPA AK } 20 \\
\text { The Netherlands } \\
\text { prospectus } \\
1992\end{array}$ & $\begin{array}{l}\text { MCPA BASF } \\
\text { Germany } \\
\text { prospectus } \\
1992\end{array}$ & $\begin{array}{l}\text { MCPA } 98 \\
\text { "Organika } \\
\text { Sarzyna" } \\
1995\end{array}$ \\
\hline & & \multicolumn{4}{|c|}{ [\%] } \\
\hline 1 & MCPA & $85-90$ & 96.0 & 94.0 & $97-98$ \\
\hline 2 & $\begin{array}{c}\text { 6-chloro-2- } \\
\text { methylphenoxyacetic } \\
\text { acid }\end{array}$ & $8-14$ & 1.0 & 1.5 & 0.7 \\
\hline 3 & $\begin{array}{l}\text { 2-methylphenoxyacetic } \\
\text { acid (MPA) }\end{array}$ & 2 & 1.0 & 1.5 & 0.2 \\
\hline 4 & $\begin{array}{l}\text { 4,6-dichloro-2- } \\
\text { methylphenoxyacetic } \\
\text { acid }\end{array}$ & 2 & 1.5 & 2.5 & 0.2 \\
\hline 5 & chlorocresols & $1-3$ & 0.5 & 0.5 & traces \\
\hline
\end{tabular}

Table 1. Comparison of MCPA quality standards. 
MCPA 98 authors have won a series of awards in national competitions for the technical and ecological level of technologies.

\section{2,4-D}

In Poland in a short time after the publication of Hamner and Tukey in Science (Hamner, Tukey, 1944) about the discovery of selective chemical herbicide 2,4-D there was started research on production and agricultural use of 2,4-D. 2,4-dichlorophenoxyacetic acid and its sodium salt are marked with the symbol 2,4-D. The dynamic development of technology and production of 2,4-D and its derivatives in our country is a constant keeping pace with the growing needs of agriculture. Sodium salt 2,4-D („Pielik”), the first modern chemical selective herbicide in the domestic market, quickly became a strategical item in agricultural cultivation. In the years 1952-53 in the Chemical Plant "Rokita”, an experimental production of 20-30 tons per year according to the technology developed in the Intitute of Industrial Organic Chemistry was launched (Hirszowski, Moszczyński, 1952).

The technology was based on the reaction of dichlorophenol (2,4-DCP) with chloroacetic acid (MCAA):

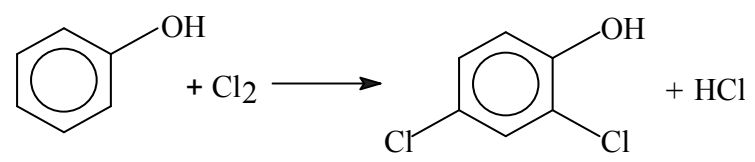

2,4-dichlorophenol

$88-90 \%$ of isomer $2,4-$<smiles>NC(=O)COc1ccc(Cl)cc1Cl</smiles>

MCAA

2,4-D $88-90 \%$ izomer 2,4-

96\% 2,4-D after crystalization from water

In 1960 in the Chemical Plants „Rokita”, a production installation of 500 tons per year was launched. One year later $1 / 2$-technique, and in 1964 a technical installation of esters 2,4-D, so called Pieliki Płynne. In 1968 in IPO there was developed the technology of technical enrichment of $90 \%$ 2,4-DCP with the help of vacuum rectification. The process turned out to be highly energy-consuming and costly. Because of similar boiling temperatures of 4-chloro2,4- and 2,6-dichlorophenols within the limits of $210-220^{\circ} \mathrm{C}$, strongly corrosive for the equipment and generating $15 \%$ of chlorophenols in the form of cube residue. In that time we did not have the knowledge about the possibility of forming dioxines in the process of chlorophenols rectification.

The turning point in the production and usage of 2,4-D occurred after the appearance and launching production of dimethylamine salt, so called Aminopielik in 1976. Aminopieliks 
are liquid preparations soluble in water, easy to use and prepare working liquids. Previously used sodium salt 2,4-D, so called Pielik, in the form of powder was poorly soluble in water, and in hard water residues of magnesium, calcium and iron salt were precipitated. In 1968 a brand new production installation 3000 tons per year was launched. As was shown in the diagram above, the synthesis of 2,4-D is based on two subsequent reactions of chlorination and condensation. This method is used by producers of 2,4-D in all countries, invariably since the first synthesis published in 1941 by J. Pokorny (Pokorny, 1941). Below, this technology is referred to as "classical". This method is based on easily available resources and the standard prodution equipment, which makes it generally accessible. A disadvantage to this method is the low quality of the product, burdened with $10-12 \%$ of undesired chlorophenoxyacetic acids, as well as free chlorophenols.

In the process of production as a result of standard purification of the product with the method of crystallization and washing there are originated 15 tons of wastes per 1 ton of 2,4D, burdened with chloroorganics, chlorophenoxyacetic acids, chlorophenols, glycolic acid and sodium chloride. With multi-thousand scale of production, it means a serious environmental problem. For several thousand tons of annual production for many years there were created many thousand tons of wastes in the solid form and in liquid wastes. In some manufactured units there was confirmed the presence of nanogram quantities of highly toxic dioxines. Technology 2,4-D required research and solutions eliminating dioxines. Thermal processing, including burning of chloroorganic compounds, particularly chlorophenols, conduces originating dioxines. For some period waste chlorophenols were separated from the liquid wastes and chlorinated up to pentachlorophenol PCF, a known fungicide used mainly for the preservation of railway sleepers. In the first period in the installation 500 tons of 2,4-D per year, chlorophenol wastes were oxygenated with sodium hypochlorite on separated uncovered ground fields, a technology of Ostrowska J. IPO. The breakthrough occurred only after condensation was mastered at the beginning of the nineties, thanks to using several metre long reactors with stirrers for the reaction of disintegration of chlorophenols with sodium hypochlorite and additional cleaning of liquid wastes on biological treatment plant.

The border of purity of 2,4-D in the classical technology is determined by $90 \%$ of isomer 2,4$\mathrm{DF}$ in the process of phenol chlorination and $96 \%$ of the active substance in acid and preparations 2,4-D after crystallization and washing.

\begin{tabular}{|l|c|}
\hline \multicolumn{2}{|c|}{ Composition of 2,4-D obtained in the classical technology } \\
\hline [\% GC] & 0.3 \\
chlorophenols & 2.0 \\
p-chlorophenoxyacetic acid & 0.4 \\
2,6-di chlorophenoxyacetic acid & 0.9 \\
2,4- di chlorophenoxyacetic acid & 95.6 \\
2,4,6-tri chlorophenoxyacetic acid & 0.3 \\
\hline
\end{tabular}

Table 2. 2,4-D obtained in the classical technology. (Białek, Moszczyński, 2009).

For many years of production of 2,4-D on bigger and bigger installations, apart from the cumulation of wastes, a weak link was the poor efficiency of condensation reaction, maximum $90 \%$ of calculated on 2,4-dichlorophenol. In particular manufactured units, it 
varied up to several per cent. The reacting mass, initially thin, sometimes as a result of a violent reaction and salting out the product, was getting thick so quickly that it could not be stirred and it was thrown out of the hatchway from the reactor. Never ending experiments with a change of concentration and order of introducing products, molar ratio, temperature and height of $\mathrm{pH}$ gave no results. During the synthesis, in the course of reacting of chloroacetic acid $\mathrm{pH}$ was changing, which required adding sodium lye. The measurement and adjustment of $\mathrm{pH}$ was done by hand and as a rule - delayed in relation to the speed of reaction. As it was mentioned above, in "Organika Sarzyna" was produced since 1962 on IPO technology 4-chloro-2-methylphenoxyacetic acid (MCPA, Chwastoks). In the reaction of condensation of 4-chloro-2-methylphenol with chloroacetic acid there occurred similar difficulties. They were mastered only after partial continuity of the process and using automatic adjustment of $\mathrm{pH}$ with the help of $\mathrm{pH}$-metre controlling the dispensing of MCAA and sodium lye.

The causes of difficulties occurring at MCAA and phenols condensation were only explained by the research of Moszczyński over the mechanism of the main reaction and the competitive MCAA hydrolysis reaction depicted before (Moszczyński, 1999). The research concerned the reaction of $o$-krezol with chloroacetic acid, but they are of a general nature and they can be related to 2,4-dichlorophenol (2,4-D) and other alkilo- and chlorophenols. Particular phenols depending on the substituents and solubility of the final chlorophenoxyacetic acid react in a slightly different way. The maximum industrial capacity of condensation in MPA synthesis is $92 \%$, while in 2,4-D synthesis $97 \%$ is achieved.

The composition of mass after condensation of raw 2,4-dichlorophenol with MCAA acid was shown below in table 3 .

\begin{tabular}{|c|c|}
\hline Composition of post-condensation mass & {$[\% \mathrm{GC}]$} \\
\hline o-chlorophenoxyacetic acid & 2.5 \\
p-chlorophenoxyacetic acid & 0.5 \\
2,6-dichlorophenoxyacetic acid & 7.4 \\
2,4-dichlorophenoxyacetic acid & 84.6 \\
2,4,6-trichlorophenoxyacetic acid & 1.2 \\
\hline o-chlorophenol & 0.0 \\
2,4-dichlorophenol & 2.2 \\
p-chlorophenol & 0.0 \\
2,6-dichlorophenol & 1.1 \\
2,4,6-trichlorophenol & 0.4 \\
\hline \multicolumn{2}{|c|}{ NaCl } \\
glycolic acid \\
water \\
\hline
\end{tabular}

Table 3. Composition of reaction mass after condensation of raw 89\% 2,4-DCP with MCAA.

Purification of acid with crystallization method has a limited efficiency. Isomer 2,6 is easily eliminated, while 2-chlorophenoxyacetic acid is hard to dissolve and remains in 2,4-D. 2,4-D of $96 \%$ purity of active substance is obtained. Rectification of about $89 \%$ raw 2,4dichlorophenol is non-economical and threatened with originating dioxines in cube residue. The difficulty in mastering the technology of selective chlorination, purifying raw $89 \% 2,4-$ 
dichlorophenol or technical 2,4-D acid is soundly confirmed by the EU position regarding purity of commercial 2,4-D and its derivatives.

In the countries of the European Union, after the process of verification and re-registration according to the directive 91/414/EWG, only preparations of the highest quality were allowed into the market, broadly tested, man friendly and natural environment friendly. In the nineties, over one half of active substances used in preparations of plant protection was recalled from sales. With allowing a plant protection agent into the market full chemical specification and toxicity tests of all pollutions of the active substance which were found in the quantity of over $0,1 \%$ were required.

In the meantime, the working team for toxicological and ecotoxicological evaluation appointed under directive 91/414 EEC (over 200 of open and closed sorts of research) 2,4-D, consisting of 12 producers and suppliers of preparation 2,4-D in the European Union, including DowElanco Europe UK, Nufarm-Agrolinz Austria, Rhone-Poulenc France and AH Marks Co Ltd. UK submitted to the European Committee for registration 2,4-D of the quality of $96 \%$ of active substance. This standard was approved for UE producers by the directive 2001/103/EC of 28.11.2001. Maintaining the traditional standard $96 \%$ of active substance 2,4-D, in spite of a great pressure of environmentalists, shows difficulties in obtaining product of a higher purity.

Moszczyński and Białek have conducted a vast research on selectivity of reaction of phenol chlorination to 2,4-dichlorophenol (Białek, Moszczyński, 2009).

Phenol is a substrate which easily undergoes electrophylic substitution in aromatic ring. Additional pair of electrons from hydroxyl group after delocalization and because of messomerism shifts to moves in aromatic ring which results in higher density of electrons in ortho- and para- positions.<smiles>Oc1ccccc1I</smiles>

Substitution in the ring with an electrophilic agent is fast but not regio- and chemoselective. Just after using $1 \mathrm{M}$ of chlorine for $1 \mathrm{M}$ of phenol a mixture of six products is formed (Watson, 1985).

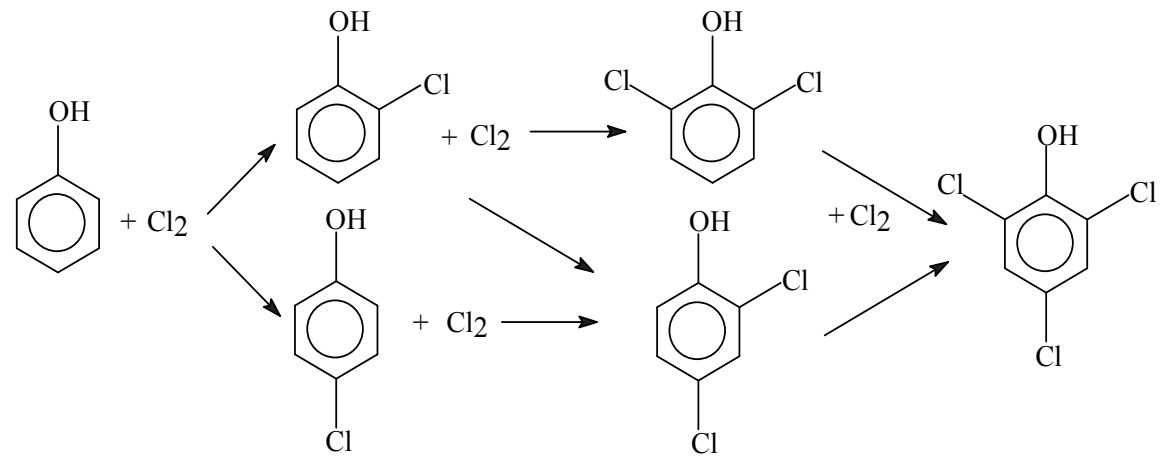


The following conclusion can be drawn from the scheme above: obtaining $p$-chlorophenol as an intermediate product in synthesis of 2,4-dichlorophenol is much more advantageous than obtaining o-chlorophenol which is followed by forming 2,4-dichlorophenol and 2,4,6trichlorophenol or even 2,6- dichlorophenol.

It is commonly known that many factors are included in the selectivity of reaction. Electron density in the substrat molecule - active phenol centres are located in the position ortho-, para- with preference for para- . The dissociation of hydroxyl group in phenol in different conditions of $\mathrm{pH}$ influences the orientation of electrophilic substitution. The activity of electrophilic agent is of crucial significance has. Chlorine molecules are a strong electrophilic agent reacting violently with active aromatic substrats. The decisive significance should be ascribed to steric effect and catalysts. Intermolecular hydrogen bondings through hydroxyl group are formed in melted phenol. The association of molecules makes it more difficult to replace in the position ortho-. A similar effect is achieved at phenol chlorination in strong acids and polar proton dissolvents. The presence of hydrogen bondings in phenols was confirmed by IR methods and proton NMR method.

Our research mostly concerned catalysts and chlorinating agents, including high-molecular ones.

It is not necessary to use catalyst during the synthesis of 2,4-dichlorophenol from melted phenol and gaseous chlorine. The process of chlorination stops at 2,4,6-trichlorophenol. Substitution of next chlorine atoms is only possible when Friedel-Crafts catalysts are used. It was stated that Lewis acids used at chlorination of less active substrates do not influence the selectivity of substitution of highly reactive phenols. Catalysts from amines group direct substituents into ortho- position. Catalysts used by Moszczyński in MPA production appeared to be totally inactive. Sulphur catalysts have a limited directing effect. The combination of Lewis catalysts with sulphur compounds resulted with a high regioselectivity into para- position. Probably in the reaction a high-molecular complex is originated, where the catalytic effect interferes with the steric effect.

There were also performed tests of chlorination with the reverse method, i.e. phenoxyacetic acid (PA). Przondo, in cooperation with fellow workers in the installation $1 / 2$-technical in Chemical Plants "Rokita”, did research on chlorination of PA acid with chlorine in alkaline water solution. Satisfactory results were not achieved. The process required significant dilutions of the reaction mass. The technology appeared to be highly waste-generating and the selectivity of chlorination not much better than at phenol chlorination (Dudycz et al. 1985).

Our team IPO and Rokita continued research on the reversed process. Using tert-butyl hypochlorite in the place of chlorine $(\mathrm{t}-\mathrm{BuOCl})$ of spatially developed molecule. A high selectivity of chlorination was achieved (98\%) and purity of 2,4-D up to $99 \%$ of active substance. A very high selectivity of chlorination reaction is the result of the interference of two steric effects - side chain and volumetric molecule t-BuOCl (Moszczyński et al. 2008). A negative side to the technology is the necessity of operating flammable $\mathrm{t}-\mathrm{BuOCl}$ and $\mathrm{t}$ $\mathrm{BuOH}$.

A technology based on sulfuryl chloride was developed and confirmed in the $1 / 2$ technical scale results presented by Watson (Watson, 1974). The process is easy to implement and control. A negative side is the necessity of $\mathrm{SO}_{2}$ recycling. 
Three new methods of 2,4-D synthesis were developed, each of them of $>95 \%$ selectivity. The barrier of $90 \%$ selectivity of isomer 2,4-D in phenol chlorination was lifted. Results were shown below in table 4 .

\begin{tabular}{|c|c|c|c|c|}
\hline $\begin{array}{c}\text { Chlorinating } \\
\text { agent, catalyst, }\end{array}$ & $\mathrm{Cl}_{2}$ & $\begin{array}{c}\mathrm{Cl}_{2} \\
\text { catalytic complex, } \\
\text { Lewis acids, } \\
\text { sulphur } \\
\text { compounds }\end{array}$ & $\begin{array}{c}\mathrm{SO}_{2} \mathrm{Cl}_{2} \\
\text { catalytic complex }\end{array}$ & $\begin{array}{c}\text { tert-BuOCl } \\
\text { phenoxyacetic } \\
\text { acid, reverse } \\
\text { method }\end{array}$ \\
\hline $\begin{array}{c}\text { Selectivity of } \\
\text { chlorination } \\
{[\%]}\end{array}$ & 90 & 96 & 98 & 98 \\
\hline $\begin{array}{c}\text { Production } \\
\text { scale }\end{array}$ & industrial & $\begin{array}{c}\text { industrial } \\
\text { (Moszczynski et al., } \\
\text { 2002) }\end{array}$ & $\begin{array}{c}\text { experimental } \\
\text { (Moszczyński et } \\
\text { al., 2009) }\end{array}$ & laboratory \\
\hline
\end{tabular}

Table 4. Progress in selectivity of the process of chlorination in technology 2,4-D.

While discussing the technology of production of 2,4-dichlorophenol, the problem of trace pollutions must be mentioned, which includes remains of catalyst, present always in industrial water iron, polychlorinated compounds, cyclohexenones derivatives. There may also appear polychlorodibenzodioxines and polychlorodibenzofurans. Trace pollutions in 2,4-DCP are undesired, because they influence the quality and stability of 2,4-D. Iron compounds may worsen the hue, remains of sulphur catalysts - odour, form during storing liquid forms slimy residues and also, as an effect, decrease the durability of 2,4-D preparations. Used by some 2,4-D producers, the vacuum rectification of technical 2,4-DCP is efficient, but it threatens with dioxines forming. In the tests of vacuum rectification of technical 2,4-dichlorophenol there was formed about $15 \%$ of post-destillation tars, containing significant quantities of dioxines, including the most toxic 2,3,7,8-TeCDD and TeCDF, which was shown below in table 5 .

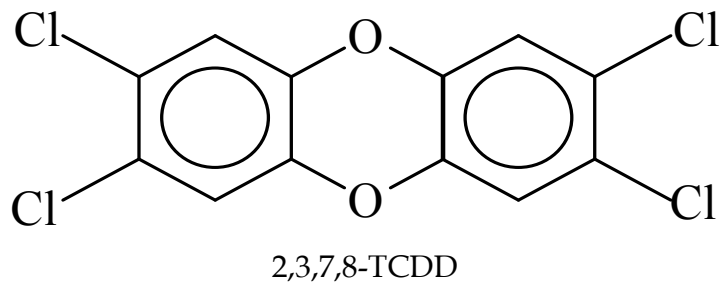

Authors have developed the technology of removing catalysts and trace pollutions (Moszczyński et al. 2005).

2,4-dichlorophenol obtained with the method of phenol chlorination in the presence of catalysts is washed off with mineral acid, it is neutralized to $\mathrm{pH}>10,5$ and dilutes with water to $50 \%$. A suspension of mineral sorbents is introduced to chlorophenolate obtained in this way. Chlorophenolate with sorbents is stirred for 30 minutes and the introduced sorbents are filtered, which are then destroyed thermally. 


\begin{tabular}{|c|c|c|c|}
\hline $\begin{array}{c}\text { Congener } \\
\text { PCDD / PCDF }\end{array}$ & $\begin{array}{c}\text { Toxicity } \\
\text { equivalency factor } \\
\text { (TEF) }\end{array}$ & $\begin{array}{c}\text { Congener content in an } \\
\text { specimen, } \mathbf{m}_{\mathbf{i}} \\
\text { [ng/g] }\end{array}$ & $\begin{array}{c}\text { Toxicity TEQ } \\
\mathbf{m}_{\mathbf{i}} \mathbf{x} \text { TEF } \\
\text { [ng-TEQ/g] }\end{array}$ \\
\hline $\mathbf{2 , 3 , 7 , 8 - T e C D D}$ & 1 & 2.32 & 2.3200 \\
\hline $\mathbf{1 , 2 , 3 , 7 , 8 - P e C D D}$ & 1 & 51.71 & 51.7100 \\
\hline $\mathbf{1 , 2 , 3 , 4 , 7 , 8 - H x C D D}$ & 0.1 & 0.28 & 0.0280 \\
\hline $\mathbf{1 , 2 , 3 , 6 , 7 , 8 - H x C D D}$ & 0.1 & 16.22 & 1.6220 \\
\hline $\mathbf{1 , 2 , 3 , 7 , 8 , 9 - H x C D D}$ & 0.1 & 6.63 & 0.6630 \\
\hline $\mathbf{1 , 2 , 3 , 4 , 6 , 7 , 8 - H p C D D}$ & 0.01 & 0.76 & 0.0076 \\
\hline $\mathbf{O C C D D}$ & 0.0001 & 3.11 & 0.0003 \\
\hline $\mathbf{2 , 3 , 7 , 8 - T e C D F}$ & 0.1 & 10.69 & 1.0690 \\
\hline $\mathbf{1 , 2 , 3 , 7 , 8 - P e C D F}$ & 0.05 & 1.45 & 0.0725 \\
\hline $\mathbf{2 , 3 , 4 , 7 , 8 - P e C D F}$ & 0.5 & 1.50 & 0.7500 \\
\hline $\mathbf{1 , 2 , 3 , 4 , 7 , 8 - H x C D F}$ & 0.1 & 0.55 & 0.0550 \\
\hline $\mathbf{1 , 2 , 3 , 6 , 7 , 8 - H x C D F}$ & 0.1 & 4.58 & 0.4580 \\
\hline $\mathbf{1 , 2 , 3 , 7 , 8 , 9 - H x C D F}$ & 0.1 & 3.16 & 0.3160 \\
\hline $\mathbf{2 , 3 , 4 , 6 , 7 , 8 - H x C D F}$ & 0.1 & 0.17 & 0.0170 \\
\hline $\mathbf{1 , 2 , 3 , 4 , 6 , 7 , 8 - H p C D F}$ & 0.01 & 5.90 & 0.0590 \\
\hline $\mathbf{1 , 2 , 3 , 4 , 7 , 8 , 9 - H p C D F}$ & 0.01 & 0.00 & 0.0000 \\
\hline OCDF & 0.0001 & 67.75 & 0.0068 \\
\hline & Result in $\mathbf{n g}$ TEQ/g & & $59.15 \pm \mathbf{0 , 0 5}$ \\
\hline
\end{tabular}

Table 5. Contents of PCDD/F in the cube residue from the destillation of 2,4-DCP (Białek, 2009).

Authors have developed the technology of removing catalysts and trace pollutions (Moszczyński et al. 2005).

2,4-dichlorophenol obtained with the method of phenol chlorination in the presence of catalysts is washed off with mineral acid, it is neutralized to $\mathrm{pH}>10,5$ and dilutes with water to $50 \%$. A suspension of mineral sorbents is introduced to chlorophenolate obtained in this way. Chlorophenolate with sorbents is stirred for 30 minutes and the introduced sorbents are filtered, which are then destroyed thermally.

Trace pollutions in purified 2,4-dichlorophenol are given below in table 6 .

\begin{tabular}{|c|c|c|}
\hline $\begin{array}{c}\text { Iron contents } \\
{[\mathrm{ppm}]}\end{array}$ & $\begin{array}{c}\text { Derivatives DPS } \\
{[\%]}\end{array}$ & $\begin{array}{c}\text { PCDD } / \mathrm{F} \\
{[\mathrm{TEQ} \mathrm{ng} / \mathrm{g}]}\end{array}$ \\
\hline$<5$ & $<0.001$ & 0.027 \\
\hline
\end{tabular}

Table 6. Trace pollutions in purified 2,4-dichlorophenol. 
The product contains trace pollutions $\mathrm{PCDD} / \mathrm{F}$ in the amount allowed by technical producers norms.

The world production of 2,4-dichlorophenol without Russia, China and India is estimated for 44000 tons per year. The current production of 2,4-DCP in Poland is 6 to 8000 tons per year. It places our country in the strict world lead. After using in 2004 a new technology of selective chlorination of phenol, two barriers were lifted: chlorination selectivity increased from 89 to $96 \%$ and the purity of commercial acid 2,4-D from 96 to $98 \%$. Waste chloroorganic compounds were decreased by one half in the production process, also organic pollutions introduced to the soil during agricultural operations were decreased by one half. Recommendations of directive 91/414 EEC on the improvement of ecological conditions in the production and usage of plant protection agents were implemented.

The author team W. Moszczyński, A. Białek, E. Makieła, B. Rippel, Listopadzki E., Okulewicz, Z. Dancewicz G. for the technology and product won prizes in national and world competitions, including:

- Złoty Orbital (Gold Orbital) of the monthly Rynek Chemiczny (Chemical Year), year 2004

- The main prize in the competition „Polish Product of the Future” ("Polski Produkt Przyszłości”) in category "Technology of the Future” („Technologia Przyszłości”) organized by the Polish Agency for Enterprise Development, year 2004

- The Gold Medal with Mentions in the World Inventions, Research and Innovations Exhibition „Brussels Eureka”, year 2005.

\section{References}

Berhenke, L. F. Britton, E. C. (1946) Effect of $\mathrm{pH}$ on Hydrolysis Rate of Chloroacetic Acid. Ind. Eng. Chem. 38 (5), pp 544-546.

Białek, A. (2009). Technology of 2,4-dichlorophenol. PhD Dissertation, Warsaw University of Technology, Warsaw.

Białek, A. Moszczyński, W. (2009). Technological aspects of the synthesis of 2,4dichlorophenol. Polish Journal Of Chemical Technology, 11, 2, pp 21-30.

Dermer, O. C. Edmison M.T. (1957) Radical Substitution In Aromatic Nuclei. Chem. Rev. 57 (1), pp 77-122.

Dudycz, R. Przondo, J. Strzyż, B. Marszal, Z. (1985). Pat. PL 243770. Metoda wytwarzania kwasu 2,4-dichlorofenoksyoctowego. Nadodrzańskie Zakłady Przemysłu Organicznego, Organika-Rokita.

Hamner, C. L. Tukey, H. (1944) The Herbicidal Action Of 2,4 Dichlorophenoxyacetic And 2,4,5 Trichlorophenoxyacetic Acid On Bindweed. Science, 100 (2590), pp 154-155.

Hirszowski, J. Moszczyński W. (1952) Dokumentacja technologiczna otrzymywania 2,4-D oraz Aneks Nr 2, Archive of The Institute of Industrial Organic Chemistry, Warsaw.

Jezierski, A. Zakrzewski, J. Moszczyński, W. (1999) Increased intensity of tert-butyloxyl radical emission in 4-chloro-2-methylphenoxy acetic acid (MCPA) synthesis. Pestic. Sci., 55, 1229-1232.

Lund, H. (1958), Chlorination of o-Cresoxyacetic Acid. A Peculiar Side Reaction. Acta Chim. Scand. 12, 793-796. 
Moszczyński, W. Ostrowski, T. Tomasik W. (1963). Pat PL 49289.

Moszczyński, W. (1971) Sprawozdanie konsultacji w Ufijskim Chimiczeskim Zawodzie, ZSRR, Archive of The Institute of Industrial Organic Chemistry, Warsaw.

Moszczyński, W. Budziar, M. Jach, J. (1975) Pat. PL 100642

Moszczyński, W. Górska, I. Jakubas, T. Piłat, W. Peć, J (1992) Pat. PL 167510

Moszczyński, W. Górska, I. Jakubas, T. Piłat, W. Peć, J (1994) Pat. PL 174569

Moszczyński, W. Górska, I. Jakubas, T. Peć, J. Piłat, W. (1997) Pat. PL 185459

Moszczyński, W. (1998) Prace Naukowe Instytutu Przemysłu Organicznego „Organika”, pp 57-60.

Moszczyński, W. (1999) Synthesis of 2-methyl-phenoxyacetic acid by the Williamson's reaction. Optimisation of reaction parameters by application of regression function Przem. Chem. 78/11, pp 398-400.

Moszczyński, W. Białek, A. Makieła, E. Rippel, B. Listopadzki, E. (2002) Pat. PL 354552, Method of the manufacture of 2,4-dichlorophenol.

Moszczyński, W. Białek, A. Makieła, E. Rippel, B. Okulewicz, Z. Dancewicz, G. (2005) Pat. PL 377671 Method for the manufacture of 2,4 - dichlorophenoxyacetic acid and its salts.

Moszczyński, W. Białek, A. Makieła, E. Rippel, B. (2008). Development of 2,4-D technology in Poland, Przem. Chem. (87), 7 pp 757-761.

Moszczyński, W. Białek A. Maliszewski, T. Wyrzykowska, U. (2009) Apl. Pat. PL 389029. Process for the preparation of 2,4-dichlorophenoxyacetic acid.

Moszczyński,W. Białek, A. Jakubas, T. Peć, J. (2010) Production of 4-chloro-2methylphenoxyacetic acid in Organika-Sarzyna at Nowa Sarzyna. An example of the cooperation between an R\&D institute and chemical company. Przem. Chem. 89/2, pp 124-127.

Pokorny R. (1941) New Compounds. Some Chlorophenoxyacetic Acids. J. Am. Chem. Soc., $63(6), 1768$.

Skeeters, M. (1956). Pat. US 2740810, Preparation of 2-methyl-4-chlorophenoxyacetic acid.

Rapos, P. Kovac, J. Batora, V. (1960), Vyskumny Ustav Agrochemickiej Technologie, Sbornik prac I , Slovenska Akademie Vied, p 63, Bratislava.

Watson, W. D. (1975). Pat. US 3920757. Chlorination With Sulfuryl Chloride.

Watson, W. D. (1985). Regioselective para-chlorination of activated aromatic compounds. J. Org. Chem., 1985, 50 (12), pp 2145-2148 


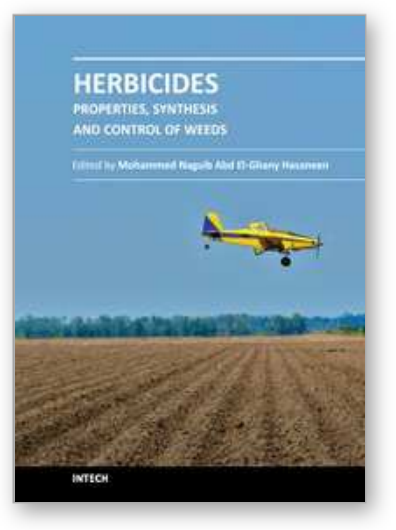

\author{
Herbicides - Properties, Synthesis and Control of Weeds \\ Edited by Dr. Mohammed Nagib Hasaneen
}

ISBN 978-953-307-803-8

Hard cover, 492 pages

Publisher InTech

Published online 13, January, 2012

Published in print edition January, 2012

This book is divided into two sections namely: synthesis and properties of herbicides and herbicidal control of weeds. Chapters 1 to 11 deal with the study of different synthetic pathways of certain herbicides and the physical and chemical properties of other synthesized herbicides. The other 14 chapters (12-25) discussed the different methods by which each herbicide controls specific weed population. The overall purpose of the book, is to show properties and characterization of herbicides, the physical and chemical properties of selected types of herbicides, and the influence of certain herbicides on soil physical and chemical properties on microflora. In addition, an evaluation of the degree of contamination of either soils and/or crops by herbicides is discussed alongside an investigation into the performance and photochemistry of herbicides and the fate of excess herbicides in soils and field crops.

\title{
How to reference
}

In order to correctly reference this scholarly work, feel free to copy and paste the following:

Wiesław Moszczyński and Arkadiusz Białek (2012). Ecological Production Technology of Phenoxyacetic Herbicides MCPA and 2,4-D in the Highest World Standard, Herbicides - Properties, Synthesis and Control of Weeds, Dr. Mohammed Nagib Hasaneen (Ed.), ISBN: 978-953-307-803-8, InTech, Available from: http://www.intechopen.com/books/herbicides-properties-synthesis-and-control-of-weeds/ecological-productiontechnology-of-phenoxyacetic-herbicides-mcpa-and-2-4-d-in-the-highest-world-sta

\section{INTECH}

open science | open minds

\section{InTech Europe}

University Campus STeP Ri

Slavka Krautzeka 83/A

51000 Rijeka, Croatia

Phone: +385 (51) 770447

Fax: +385 (51) 686166

www.intechopen.com

\section{InTech China}

Unit 405, Office Block, Hotel Equatorial Shanghai

No.65, Yan An Road (West), Shanghai, 200040, China

中国上海市延安西路65号上海国际贵都大饭店办公楼 405 单元

Phone: +86-21-62489820

Fax: $+86-21-62489821$ 
(C) 2012 The Author(s). Licensee IntechOpen. This is an open access article distributed under the terms of the Creative Commons Attribution 3.0 License, which permits unrestricted use, distribution, and reproduction in any medium, provided the original work is properly cited. 